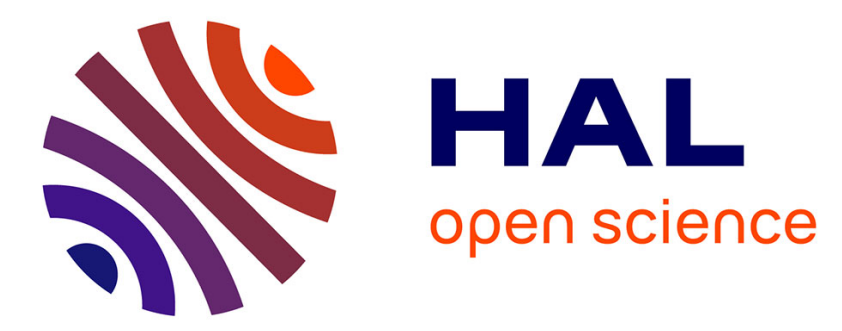

\title{
Three-Dimensional Analytical Model for an Axial-Field Magnetic Coupling
}

\author{
Bastien Dolisy, Thierry Lubin, Smail Mezani, Jean Lévêque
}

\section{To cite this version:}

Bastien Dolisy, Thierry Lubin, Smail Mezani, Jean Lévêque. Three-Dimensional Analytical Model for an Axial-Field Magnetic Coupling. Progress In Electromagnetics Research M, 2014, 35, pp.173-182. 10.2528/PIERM14031405 . hal-01011497

\section{HAL Id: hal-01011497 \\ https://hal.science/hal-01011497}

Submitted on 24 Jun 2014

HAL is a multi-disciplinary open access archive for the deposit and dissemination of scientific research documents, whether they are published or not. The documents may come from teaching and research institutions in France or abroad, or from public or private research centers.
L'archive ouverte pluridisciplinaire HAL, est destinée au dépôt et à la diffusion de documents scientifiques de niveau recherche, publiés ou non, émanant des établissements d'enseignement et de recherche français ou étrangers, des laboratoires publics ou privés. 


\title{
Three-Dimensional Analytical Model for an Axial-Field Magnetic Coupling
}

\author{
Bastien Dolisy ${ }^{*}$, Thierry Lubin, Smail Mezani, and Jean Lévêque
}

\begin{abstract}
In this paper, we propose an analytical method for modeling a permanent magnets axial field magnetic coupling. The three-dimensional model takes into account the radial fringing effects of the coupler. The analytical solution requires resolving the Laplace equation in low permeability subdomains. The magnetic field calculation allows the determination of global quantities like axial force and torque. 3D finite element computations as well as measurements validate the proposed model.
\end{abstract}

\section{INTRODUCTION}

Magnetic couplings are used to transmit torque from a prime mover to its load without mechanical contact. This is useful in applications requiring hermetic isolation between two rotary parts. In addition, the absence of mechanical contact eliminates matter's wear. This synchronous type coupling also provides intrinsic protection against overloads.

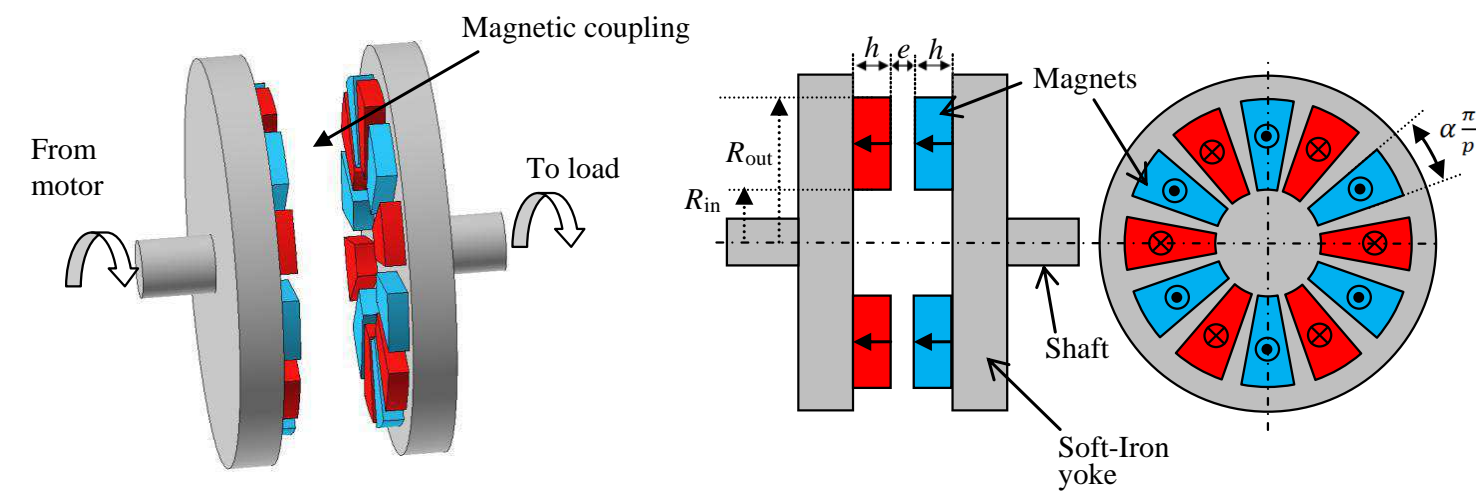

Figure 1. Structure of a magnetic coupling $(p=6)$.

The studied magnetic coupling (Figure 1) is composed of two identical rotors equipped with axially magnetized permanent magnets (PMs). The PMs are glued on an iron yoke to form a north-south alternating polarity. The two rotors are separated by an air gap. The torque is created when the magnetic fields due to the two rotors are shifted by an angle $\varphi$, called the load angle.

The aim of this paper is to develop an exact 3D analytical model which allows the computation of the magnetic field distribution, the axial force and the torque.

In the literature, there are two types of analytical modeling for magnetic actuator:

Received 14 March 2014, Accepted 4 April 2014, Scheduled 6 April 2014

* Corresponding author: Bastien Dolisy (bastien.dolisy@univ-lorraine.fr).

The authors are with the Laboratoire GREEN, Université de Lorraine, Faculté des Sciences et Technologies, BP 239, 54506, France 
- 3D Modeling is based on Amperien model using Biot-Savart law or on Coulombian model using charge surfaces [1-16]. These methods can be used only in free space without ferromagnetic material. To take into account the magnetic yoke, the method of images is used.

- Fourier analysis based on the resolution of Maxwell's equations by the method of separation of variables [17-24]. This method assumes an infinite permeability of the ferromagnetic materials so iron faces appear as homogeneous boundary conditions. Periodicities can also be taken into account. Analytical modeling based on Fourier method is widely used. Most of the computations are done in 2D so neglecting edge effects $[19,20]$. To consider $3 \mathrm{D}$ effects in a 2D model, a multi-slice approach can be used so better results can be obtained [21,22]. Three-dimensional models [23, 24] are also developed for electrical machines analysis but the slotting effects are taken into account using the Carter coefficient.

In this paper, we present a 3D analytical approach based on the resolution of Maxwell's equations. The 3D model takes into account the edges effects. The analytical model is validated through $3 \mathrm{D} F E$ computations and experiments.

\section{PROBLEM DESCRIPTION AND ASSUMPTIONS}

The magnetic coupling is only composed of permanent magnets, ferromagnetic yokes and air. Hence, a magnetic scalar formulation is used. The magnetic field $\vec{H}$ and the scalar potential $V$ are related by

$$
\vec{H}=-\overrightarrow{\operatorname{grad}}(V)
$$

In the different media, the flux density is

$$
\begin{aligned}
& \text { In the air: } \vec{B}=\mu_{0} \cdot \vec{H} \\
& \text { In the magnet: } \vec{B}=\mu_{0} \cdot \mu_{r} \cdot(\vec{H}+\vec{M})
\end{aligned}
$$

where $\mu_{0}$ and $\mu_{r}$ are the vacuum permeability and the relative permeability of the magnets and $\vec{M}$ is the magnetization.

When cylindrical coordinates are use, the solutions arising from the resolution of the PDE contain Bessel's functions. This leads to some numerical difficulties and a lack of accuracy since only few harmonics can be used. These problems decrease the reliability of the design tool. A linearization assumption at the mean radius (Figure 2) is used here to overcome the problems encountered using cylindrical coordinates. This assumption is valid if the curvature effects are ignored. Of course, this is true for most electromechanical devices because the air gap thickness is usually much lower than the other dimensions of the system. This issue will be discussed in Section 4.2.

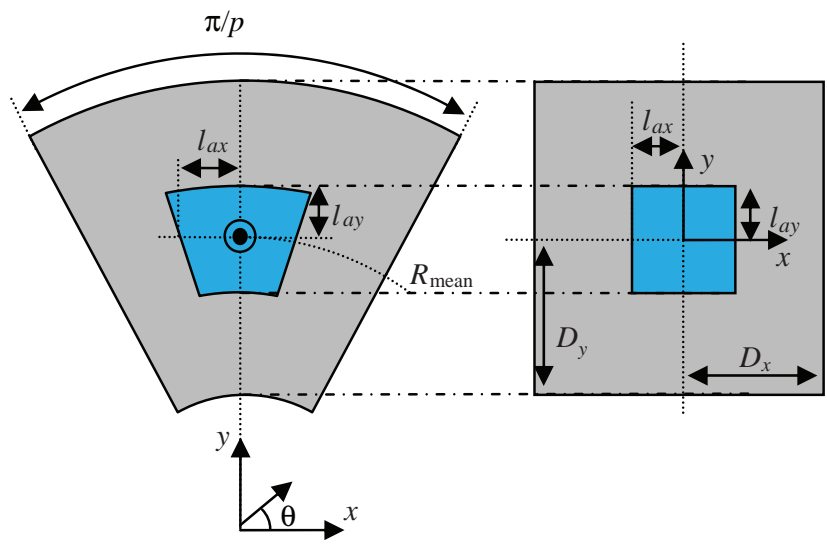

Figure 2. Linearization at the mean radius.

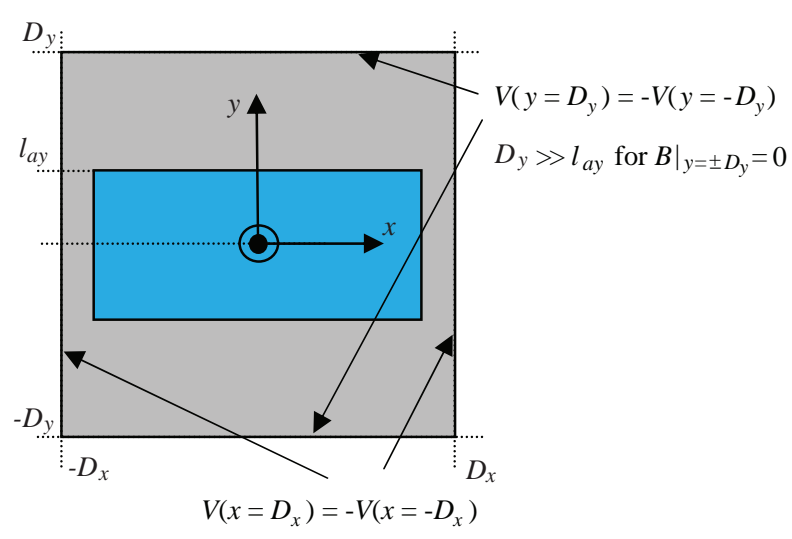

Figure 3. Anti-periodic conditions in the system. 


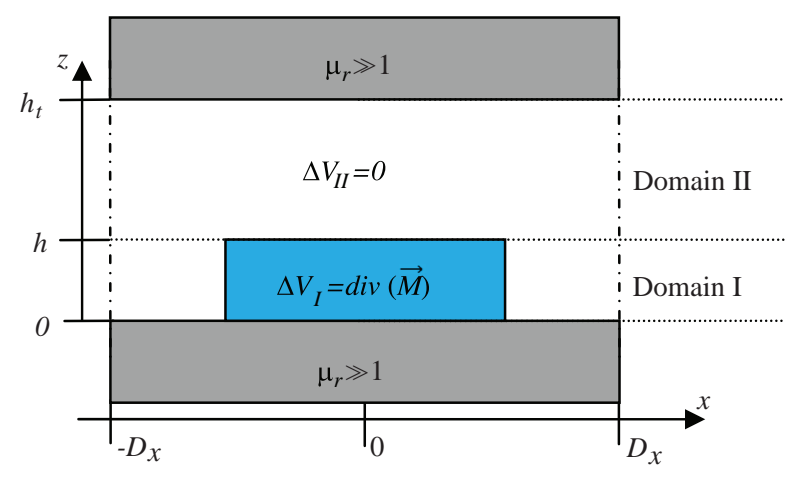

Figure 4. Resolution domain in the $(x, z)$ plan.

Figure 3 shows the studied domain in the $x y$ plan together with the adopted periodicity conditions. Only one pole is considered with anti-periodic boundary conditions along $x$. The anti-periodicity along the $y$ axis is a fictitious one adopted to facilitate the computation. By setting $D_{y} \gg l_{a y}$, this condition is equivalent to a more physical condition which is $B_{y}=0$ at $y= \pm D_{y}$.

The permeability of ferromagnetic parts (yokes) is considered infinite $\left(\mu_{r} \gg 1\right)$. Hence, at the interface between the iron and the air, we impose the orthogonality of the flux lines by

$$
\vec{n} \wedge \vec{H}=0
$$

where $n$ is the outward normal to the considered surface.

The permeability of the permanent magnets $(\mathrm{NdFeB})$ is considered equal to that of air $\left(\mu_{r}=1\right)$.

The smooth geometry of the coupling (no slotting effects) allows us to calculate only the field created by one rotor (the magnets on the other rotor are switched off). The field due to the second rotor is then deduced from the computed solution which is shifted by the angle $\varphi$. The total field is obtained by superposing the two solutions.

Figure 4 shows the whole domain of resolution taking into account all the assumptions and the equations to solve. $\vec{M}$.

Domain I $(0 \leq z \leq h)$ corresponds to the first rotor magnet region whose magnetization is noted

Domain II $\left(h \leq z \leq h_{t}\right)$ is an air region composed of the airgap and the second rotor magnet whose magnetization is set to zero.

The geometrical parameters gathered from Figure 2 and Figure 4, are:

$2 \cdot D_{x}$ : Length along the $x$-axis,

$2 \cdot D_{y}$ : Length along the $y$-axis,

$2 \cdot l_{a x}$ : Length of the magnet along the $x$-axis,

$2 \cdot l_{a y}$ : Length of the magnet along the $y$-axis,

$h$ : Height of the magnet,

$h_{t}$ : Total height of the system.

\section{MAGNETIC FIELD CALCULATION}

The method of separation of variables is used to solve the PDEs in the two studied subdomains.

3.1. Domain I $(0 \leq \boldsymbol{z} \leq \boldsymbol{h})$

In the domain I, we have to solve the following equation

$$
\frac{\partial^{2} V_{I}}{\partial x^{2}}+\frac{\partial^{2} V_{I}}{\partial y^{2}}+\frac{\partial^{2} V_{I}}{\partial z^{2}}=\operatorname{div}(\vec{M}) \text { for }\left\{\begin{array}{l}
-D_{x} \leq x \leq D_{x} \\
-D_{y} \leq y \leq D_{y}
\end{array}\right.
$$


The magnetization vector $\vec{M}$ has only a component in the $z$-direction $\left(\vec{M}=M_{z}(x, y) \cdot \vec{u}_{z}\right)$. In this case, the divergence term is zero so (5) reduces to a Laplace equation

$$
\frac{\partial^{2} V_{I}}{\partial x^{2}}+\frac{\partial^{2} V_{I}}{\partial y^{2}}+\frac{\partial^{2} V_{I}}{\partial z^{2}}=0
$$

The anti-periodic boundary conditions at $x= \pm D_{x}$ and $y= \pm D_{y}$ lead to

$$
\begin{aligned}
& V_{I}\left(x=D_{x}\right)=-V_{I}\left(x=-D_{x}\right) \\
& V_{I}\left(y=D_{y}\right)=-V_{I}\left(y=-D_{y}\right)
\end{aligned}
$$

By using the method of separation of variables, the solution of (6) is

$$
\begin{aligned}
V_{I}(x, y, z)= & \sum_{n=1}^{\infty} \sum_{m=1}^{\infty}\left[A_{I} \cdot e^{k \cdot z}+B_{I} \cdot e^{-k \cdot z}\right] \times\left(C_{I} \cdot \cos \left(w_{n} \cdot x\right)+D_{I} \cdot \sin \left(w_{n} \cdot x\right)\right) \\
& \times\left(E_{I} \cdot \cos \left(w_{m} \cdot y\right)+F_{I} \cdot \sin \left(w_{m} \cdot y\right)\right) \\
\text { with } w_{n}= & \frac{n \cdot \pi}{D_{x}} ; \quad w_{m}=\frac{m \cdot \pi}{D_{y}} ; \quad k=\sqrt{w_{n}^{2}+w_{m}^{2}}
\end{aligned}
$$

where the coefficients $A_{I}, B_{I}, C_{I}, D_{I}, E_{I}$ and $F_{I}$ are the constants to be determined for each harmonic orders $(n$ and $m)$.

Because of the symmetries along $x$ and $y$, the axial component of the flux density $B_{z}$ is zero at $x= \pm D_{x}$ and $y= \pm D_{y}$.

$$
\left.B_{z}\right|_{x= \pm D_{x} \& y= \pm D_{y}}=0
$$

Then, the solution given by (8) simplifies to

$$
V_{I}(x, y, z)=\sum_{n=1}^{\infty} \sum_{m=1}^{\infty}\left[A_{I} \cdot e^{k \cdot z}+B_{I} \cdot e^{-k \cdot z}\right] \times \cos \left(w_{n} \cdot x\right) \cdot \cos \left(w_{m} \cdot y\right)
$$

\subsection{Domain II $\left(h \leq z \leq h_{t}\right)$}

The Laplace equation has to be solved in this air domain

$$
\frac{\partial^{2} V_{I I}}{\partial x^{2}}+\frac{\partial^{2} V_{I I}}{\partial y^{2}}+\frac{\partial^{2} V_{I I}}{\partial z^{2}}=0 \text { for }\left\{\begin{array}{l}
-D_{x} \leq x \leq D_{x} \\
-D_{y} \leq y \leq D_{y}
\end{array}\right.
$$

Because of the symmetries described above, the solution of (11) reduces to

$$
V_{I I}(x, y, z)=\sum_{n=1}^{\infty} \sum_{m=1}^{\infty}\left[A_{I I} \cdot e^{k \cdot z}+B_{I I} \cdot e^{-k \cdot z}\right] \times \cos \left(w_{n} \cdot x\right) \cdot \cos \left(w_{m} \cdot y\right)
$$

where the coefficients $A_{I I}$ and $B_{I I}$ are constants to be determined for each harmonic orders $n$ and $m$.

\subsection{Determination of $A_{I}, B_{I}, A_{I I}$ and $B_{I I}$}

These coefficients are obtained using the interface and boundary conditions. The solutions given by (10) and (12) require the determination of $4 \times N \times M$ unknowns, where $N$ and $M$ are the number of harmonics used to solve this problem. For this purpose, the following conditions are used:

\subsubsection{Boundary Condition in Domain I at $z=0$}

We replace (1) into (4) to obtain:

$$
\begin{aligned}
& H_{x}=-\left.\frac{\partial V_{I}}{\partial x}\right|_{z=0}=0 \\
& H_{y}=-\left.\frac{\partial V_{I}}{\partial y}\right|_{z=0}=0
\end{aligned}
$$


These conditions state that the tangential magnetic field components are zero at $z=0$.

The development of these equations gives us $N \times M$ equations linking the coefficients in the domain I.

$$
A_{I}+B_{I}=0
$$

\subsubsection{Boundary Conditions in Domain II at $z=h_{t}$}

The conditions are the same as in (13), so we can deduce $N \times M$ equations linking the coefficients of the domain II.

$$
A_{I I} e^{k \cdot h_{t}}+B_{I I} e^{-k \cdot h_{t}}=0
$$

\subsubsection{Interface Conditions between Domains I and II $(z=h)$}

Domains I and II have the same magnetic permeability $\left(\mu_{r}=1\right)$, so the normal induction $\left(B_{z}\right)$ and the tangential magnetic field $\left(H_{x}\right.$ and $\left.H_{y}\right)$ of the domain I and II will be equal at $z=h$.

$$
\begin{aligned}
& \left.B_{I z}\right|_{z=h}=\left.B_{I I z}\right|_{z=h} \\
& \left.H_{I x}\right|_{z=h}=\left.H_{I I x}\right|_{z=h} \\
& \left.H_{I y}\right|_{z=h}=\left.H_{\text {IIy }}\right|_{z=h}
\end{aligned}
$$

Substituting (1), (2) and (3) into (16), yields to the following equations:

$$
\begin{aligned}
-\frac{\partial V_{I}}{\partial x} & =-\frac{\partial V_{I I}}{\partial x} \\
-\frac{\partial V_{I}}{\partial y} & =-\frac{\partial V_{I I}}{\partial y} \\
-\frac{\partial V_{I}}{\partial z}+M_{z} & =-\frac{\partial V_{I I}}{\partial z}
\end{aligned}
$$

$M_{z}$ is obtained by expanding the magnetization into a double Fourier series along the $x$ and $y$-directions in the domain I (Figure 5). The magnetization is expressed as

$$
\begin{aligned}
M_{z}(x, y) & =\sum_{n=1}^{\infty} \sum_{m=1}^{\infty} M \cdot \cos \left(w_{n} \cdot x\right) \cdot \cos \left(w_{m} \cdot y\right) \\
\text { with } M & =\frac{16 \cdot B_{r}}{\mu_{0} \cdot n \cdot m \cdot \pi^{2}} \times \sin \left(w_{n} \cdot l_{a x}\right) \cdot \sin \left(w_{m} \cdot l_{a y}\right)
\end{aligned}
$$

$B_{r}$ is the remanent flux density of the permanent magnets.

Finally, by replacing (10), (12) and (18) in (16), we obtain the $2 \times N \times M$ missing equations.

$$
\begin{aligned}
& A_{I} \cdot e^{k \cdot h a}+B_{I} \cdot e^{-k \cdot h a}-A_{I I} \cdot e^{k \cdot h a}-B_{I I} \cdot e^{-k \cdot h a}=0 \\
& k \cdot A_{I} \cdot e^{k \cdot h a}-k \cdot B_{I} \cdot e^{-k \cdot h a}-k \cdot A_{I I} \cdot e^{k \cdot h a}+k \cdot B_{I I} \cdot e^{-k \cdot h a}=M
\end{aligned}
$$

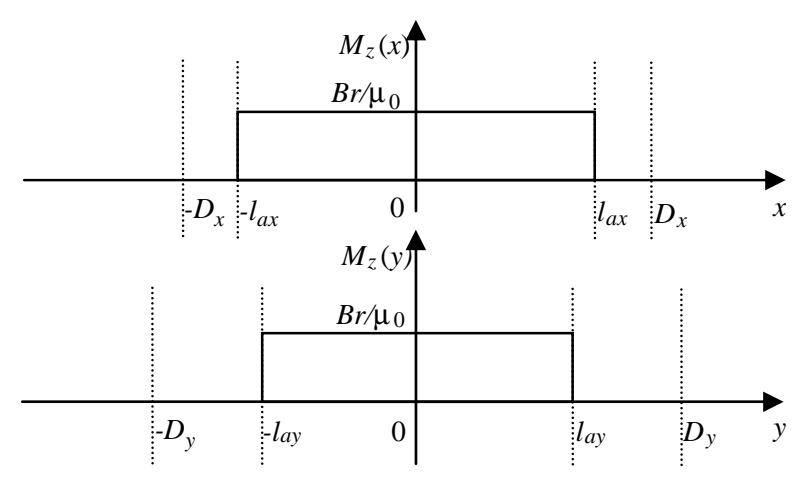

Figure 5. Magnetization $M_{z}$ as a function of $x$ and $y$. 
The coefficients $A_{I}, B_{I}, A_{I I}$ and $B_{I I}$ are calculated by solving, for each pair of harmonics $n$ and $m$, an algebraic system of linear equations arising from (14), (15) and (19).

The presented methodology concerns the determination of the solution due to a magnet in one rotor (the magnetization of the magnets on the second rotor is set to zero). The solution due to the second rotor magnets is obtained in the same way. Finally, the complete solution is obtained by superposing the two results. If one notes $\overrightarrow{B_{1}}$ the flux density due to the magnets on the first rotor, the flux density $\overrightarrow{B_{2}}$ due to the magnets on the second rotor with the spatial offset $X_{i}=R_{\text {mean }} \times \varphi$, is $\overrightarrow{B_{2}}(x, y, z)=\overrightarrow{B_{1}}\left(x^{\prime}, y, z^{\prime}\right)$ with $x^{\prime}=x-X_{i} ; z^{\prime}=-\left(z-h_{t}\right)$.

Then, the overall solution is obtained by superposition as

$$
\vec{B}(x, y, z)=\vec{B}_{1}(x, y, z)+\vec{B}_{2}(x, y, z)
$$

\section{RESULTS AND DISCUSSIONS}

In this section, we compare the results issued from the 3D analytical model to those obtained from a finite element analysis using COMSOL Multiphysics ${ }^{\circledR}$. The results are also compared to some measurements.

\subsection{Validation of the Linearized Model}

The geometrical parameters of the linearized coupling are given in Table 1. Figure 6 shows the magnetic flux densities $B_{x}, B_{y}$ and $B_{z}$ along the $x$-direction in the middle of the air gap $\left(z=h_{t} / 2\right)$ and $y=0$ with a magnet offset $X_{i}=D_{x}$. The analytical and the numerical results are in very good agreement.

Figure 7 shows the electromagnetic static forces vs. $X_{i}$ applied to one rotor pole. These forces are derived from the integration of the Maxwell stress tensor on a surface in the middle of the air gap. Unlike the $F_{x}$ force, the axial force $\left(F_{z}\right)$ has an non nil average value due to the attraction of the iron yokes.

It is important to note that the computation time of the analytical model for one position of the magnet is about 1 millisecond whereas the numerical calculation (3D mesh and resolution) takes several minutes.

\subsection{Curvature Effects}

As stated in the introduction of this paper, the linearized model ignores the curvature effects. Hence, we have to analyze the error introduced by the linearized model when evaluating the performances of a cylindrical axial coupling, for a given air gap, this error depends on the radial excursion $\left(R_{\text {out }}-R_{\text {in }}\right)$ defined in Figure 1 and on the mean pole pitch which is equal to $\left(R_{\text {out }}+R_{\text {in }}\right) \pi / 2 p$.

Table 1. Dimension of the linearized magnetic coupling.

\begin{tabular}{|c|c|c|c|}
\hline Parameter & Description & Unit & Value \\
\hline $2 \cdot D_{x}$ & Length of the domain along $x$ & $\mathrm{~mm}$ & 100 \\
\hline $2 \cdot D_{y}=8 \cdot D_{x}$ & Length of the domain along $y$ & $\mathrm{~mm}$ & 400 \\
\hline $2 \cdot l_{a x}$ & Length of the magnet along the $x$-axis & $\mathrm{mm}$ & 80 \\
\hline $2 \cdot l_{a y}$ & Length of the magnet along the $y$-axis & $\mathrm{mm}$ & 80 \\
\hline$h$ & Height of the magnet & $\mathrm{mm}$ & 15 \\
\hline$e$ & Thickness of the air gap & $\mathrm{mm}$ & 5 \\
\hline$h_{t}=2 h+e$ & Total height of the domain along $z$-axis & $\mathrm{mm}$ & 35 \\
\hline$B_{r}$ & Remanent flux density of permanent magnets & $\mathrm{T}$ & 1.2 \\
\hline$N$ & Number of harmonics along the $x$-axis & - & 30 \\
\hline$M$ & Number of harmonics along the $y$-axis & - & 30 \\
\hline
\end{tabular}




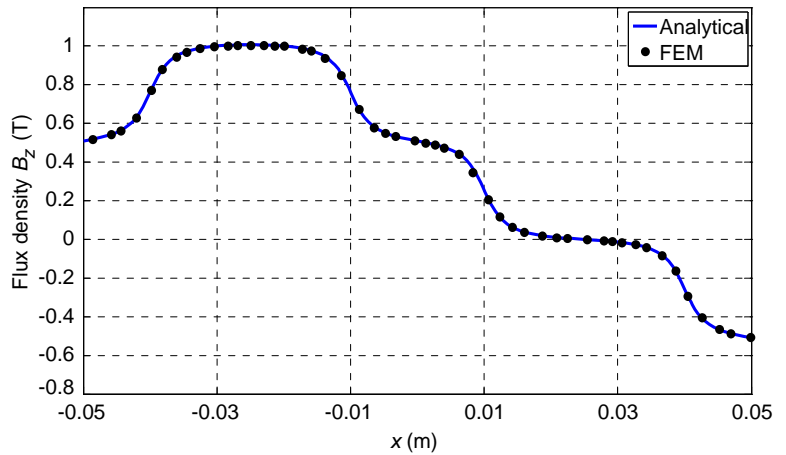

(a)

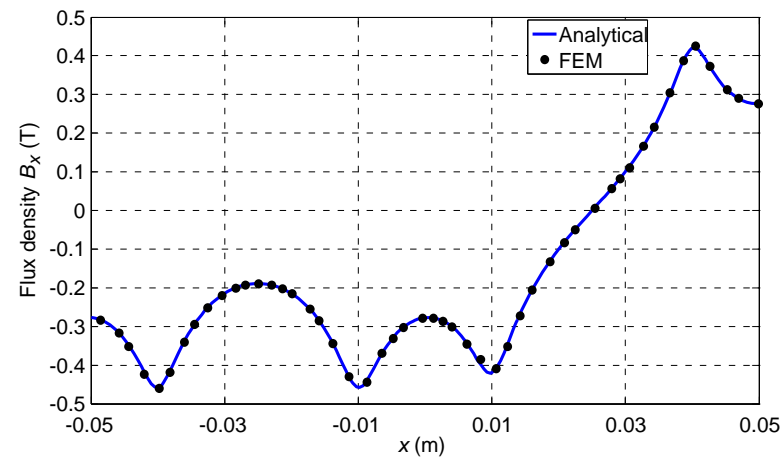

(b)

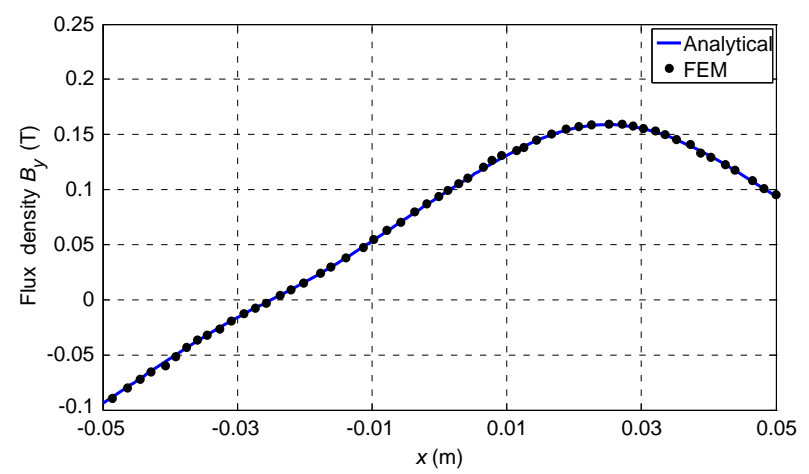

(c)

Figure 6. Flux density distribution under 1 pole in the middle of the air-gap $\left(z=h_{t} / 2\right)$ at $y=l x / 2$ : (a) $z$ component, (b) $x$ component and (c) $y$ component.

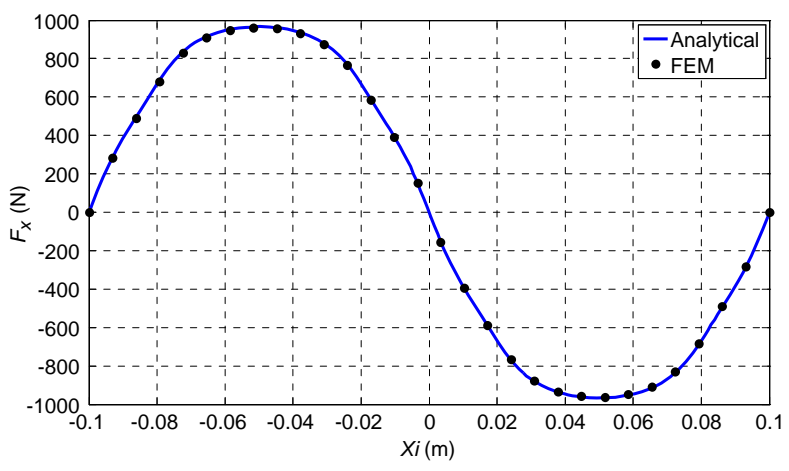

(a)

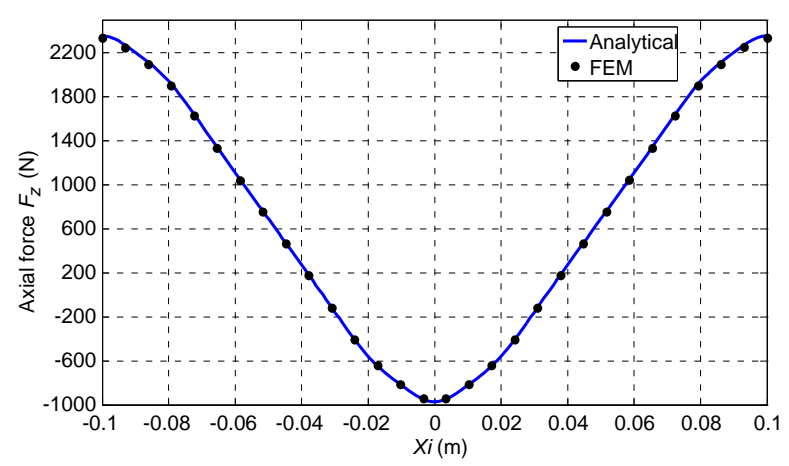

(b)

Figure 7. (a) Static forces $F_{x}$ and (b) axial force $F_{z}$.

To analyze the influence of these parameters, we introduce a dimensionless number $\lambda$ which allows comparing the pole pitch and the radial extrusion

$$
\lambda=p \cdot \frac{1-\beta}{1+\beta} \quad \text { with } \quad \beta=\frac{R_{\text {in }}}{R_{\text {out }}}
$$

Two computations are performed: the first one evaluates, by 3D FEM, the torque of the cylindrical coupling and the second one uses the analytical model to calculate the torque of the linearized cylindrical coupling. For a magnet height $h=10 \mathrm{~mm}$, we vary $R_{\text {out }}, R_{\text {in }}$ and $p$ for two values of air gap $(e=5 \mathrm{~mm}$ 
and $10 \mathrm{~mm}$ ) in the following intervals:

$$
\begin{aligned}
R_{\text {out }} & =[0.1 \mathrm{~m} \text { to } 0.3 \mathrm{~m}] \text { with a step of } 0.1 \mathrm{~m} \text { (three values); } \\
R_{\text {in }} & =\left[0.2 \times R_{\text {out }} \text { to } 0.8 \times R_{\text {out }}\right] \text { with a step of } 0.1 \times R_{\text {out }}(\text { seven values); } \\
p & =[2 \text { to } 8] \text { with a step of } 1 \text { (seven values); }
\end{aligned}
$$

This corresponds to 294 combinations.

Figure 8 shows the relative difference between the torque evaluations for different values of $\lambda$. It can be seen that the error is less than $4 \%$ for an airgap of $5 \mathrm{~mm}$. As expected, this error rises to $6 \%$ when the airgap value is $10 \mathrm{~mm}$. This demonstrates the ability of the analytical model to accurately evaluate the torque. Hence, the developed model can be used as an efficient tool for quickly sizing cylindrical magnetic couplings.

\subsection{Experimental Checking}

In this section, we compare the analytical results and some measurements carried out on a constructed magnetic coupling [19]. The dimensions of the magnetic coupling are given in Table 2. A photograph of the prototype is shown Figure 9. This coupling has a value $\lambda=2$.

Figured 10 and 11 compare the measured and the computed axial flux densities in the middle of the air gap. The measurements have been taken at no load $(\varphi=0)$ using a Hall effect probe driven by a XY displacement table. The air gap thickness is set to $e=9.5 \mathrm{~mm}$.

The calculated and the measured axial flux densities $B_{z}$ are almost identical. The small difference when evaluating $B_{z}$ along the radial coordinate is due to the curvature effects.

Figure 12 shows the static torque vs. load angle for air gap values $e=9.5 \mathrm{~mm}$ and $e=4 \mathrm{~mm}$.

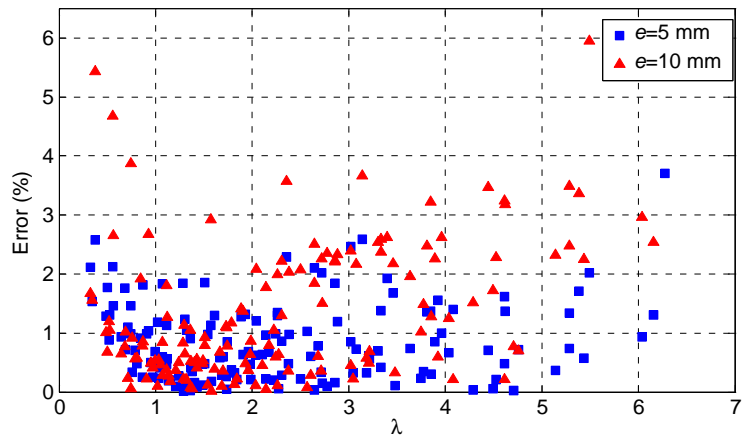

Figure 8. Error on the maximum torque when using the (linearized-analytical) and the (cylindrical-numerical) calculations.

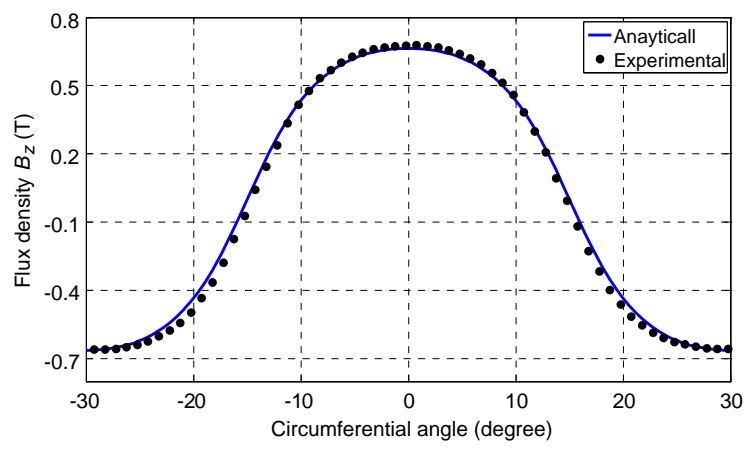

Figure 10. Axial flux density $\left(B_{z}\right)$ vs. angular position in the middle of the air gap $\left(z=h_{t} / 2\right)$ and mean radius $R_{\text {mean }}$ for $e=9.5 \mathrm{~mm}$.

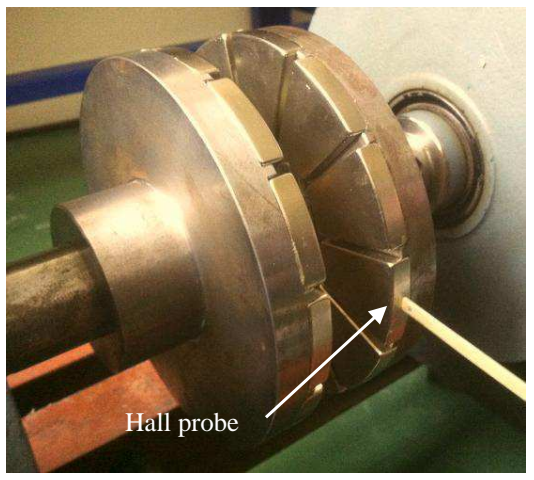

Figure 9. Demonstrator axial magnetic coupling $(p=6)$.

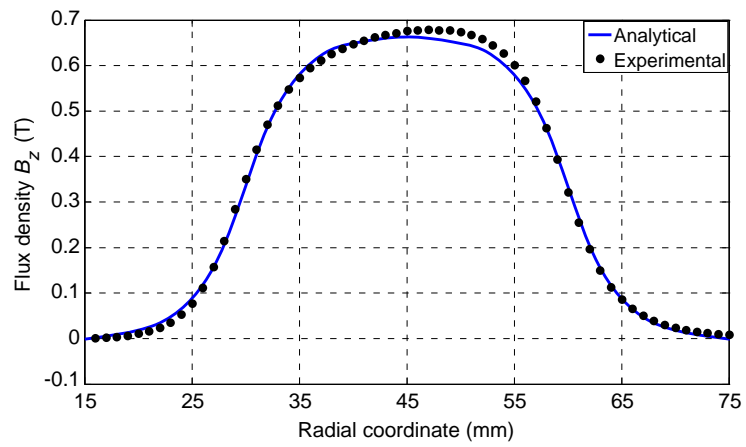

Figure 11. Axial flux density $\left(B_{z}\right)$ vs. radial coordinate in the middle of the air gap $\left(z=h_{t} / 2\right)$ at the center of the pole for $e=9.5 \mathrm{~mm}$. 
Table 2. Dimension of the magnetic coupling.

\begin{tabular}{|c|c|c|c|}
\hline Parameter & Description & Unit & Value \\
\hline$R_{\text {out }}$ & Outer radius & $\mathrm{mm}$ & 60 \\
\hline$R_{\text {in }}$ & Inner radius & $\mathrm{mm}$ & 30 \\
\hline$h$ & Magnet thickness & $\mathrm{mm}$ & 7 \\
\hline$e$ & Thickness of the air gap & $\mathrm{mm}$ & variable \\
\hline$\alpha$ & Magnet opening to pole-pitch ratio & - & 0.9 \\
\hline$p$ & Number of pole pairs & - & 6 \\
\hline$B_{r}$ & Remanence of permanent magnets & $\mathrm{T}$ & 1.25 \\
\hline
\end{tabular}

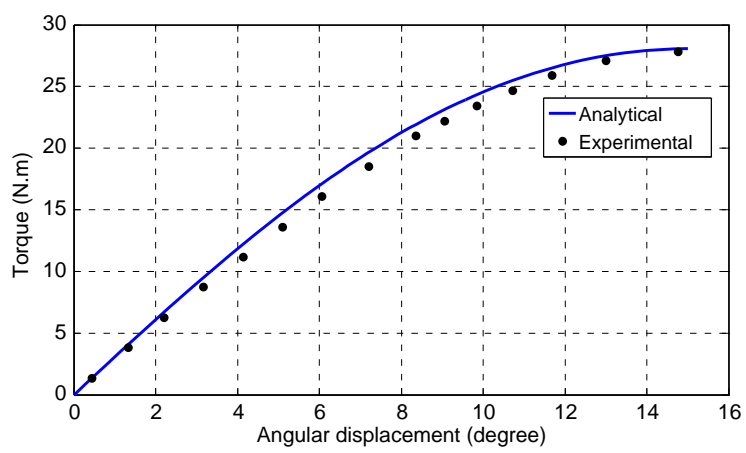

(a)

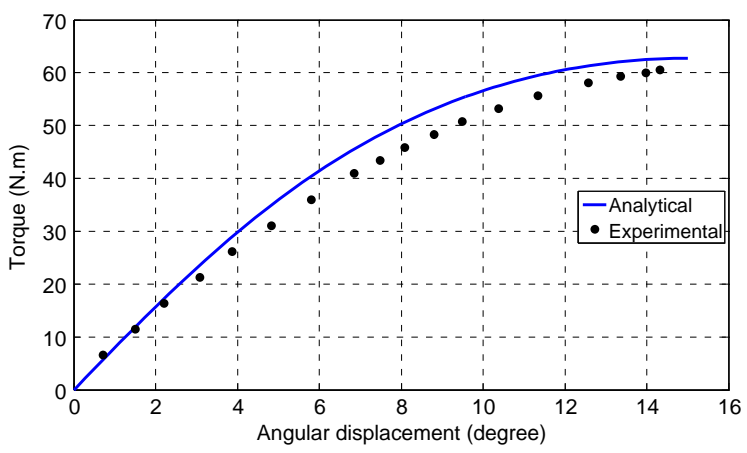

(b)

Figure 12. Static torque vs. load angle for two values of the air gap: (a) $e=9.6 \mathrm{~mm}$ and (b) $e=4 \mathrm{~mm}$.

The relative difference between the analytical results and the measurements is lower than $3 \%$ for both air gap values. The model slightly overestimates the torque.

\section{CONCLUSIONS}

In this article, we have presented an analytical model that can quickly predict the flux density distribution, the forces and the torque of PMs axial magnetic couplings. It has been shown that linearizing the actual cylindrical topology doesn't affect the accuracy of the model. In fact, several numerical and experimental checking show the ability of the developed analytical model to accurately evaluate the magnetic field distribution and the torque.

This powerful tool can then be used for fast and accurate design of PMs magnetic couplings or to be integrated within evolutionary optimization procedures.

\section{ACKNOWLEDGMENT}

The authors would like to thank the DGA (Direction Générale de l'Armement) for funding this work.

\section{REFERENCES}

1. Yonnet, J. P., "Permanent magnet bearings and couplings," IEEE Trans. Magn., Vol. 17, No. 1, 1169-1173, 1981.

2. Furlani, E. P., "Formulas for the force and torque of axial couplings," IEEE Trans. Magn., Vol. 29, No. 5, 2295-2301, Sep. 1993.

3. Yonnet, J. P., S. Hemmerlin, E. Rulliere, and G. Lemarquand, "Analytical calculation of permanent magnet couplings," IEEE Trans. Magn., Vol. 29, No. 6, 2932-2934, Nov. 1993.

4. Furlani, E., S. Reznik, and A. Kroll, "A three-dimensional field solution for radially polarized cylinders," IEEE Trans. Magn., Vol. 31, No. 1, 844-851, Jan. 1995. 
5. Furlani, E. P., R. Wang, and H. Kusnadi, "A three-dimensional model for computing the torque of radial couplings," IEEE Trans. Magn., Vol. 31, No. 5, 2522-2526, Sep. 1995.

6. Yao, Y. D., G. J. Chiou, D. R. Huang, and S. J. Wang, "Theoretical computations for the torque of magnetic coupling," IEEE Trans. Magn., Vol. 31, No. 3, 1881-1884, May 1995.

7. Waring, R., J. Hall, K. Pullen, and M. R. Etemad, "An investigation of face type magnetic couplers," Proc. Inst. Mech. Engrs, Part A, Vol. 210, No. 4, 263-272, 1996.

8. Furlani, E. P., "Analysis and optimization of synchronous couplings," J. Appl. Phys., Vol. 79, 4692-4694, 1996.

9. Furlani, E. P. and M. A. Knewtson, "A three-dimensional field solution for permanent-magnet axial-field motors," IEEE Trans. Magn., Vol. 33, No. 3, 2322-2325, May 1997.

10. Elies, P. and G. Lemarquand, "Analytical optimization of the torque of a permanent-magnet coaxial synchronous coupling," IEEE Trans. Magn., Vol. 34, No. 4, 2267-2273, Jul. 1998.

11. Charpentier, J. F. and G. Lemarquand, "Optimal design of cylindrical air-gap synchronous permanent magnet couplings," IEEE Trans. Magn., Vol. 35, No. 2, 1037-1046, Mar. 1999.

12. Charpentier, J. F., N. Fadli, and J. Jennane, "Study of ironless permanent magnet devices being both a coupling and an axial bearing for naval propulsion," IEEE Trans. Magn., Vol. 39, No. 5, 3235-3237, Sep. 2003.

13. Rakotoarison, H. L., J. P. Yonnet, and B. Delinchant, "Using Coulombian approach for modelling scalar potential and magnetic field of a permanent magnet with radial polarization," IEEE Trans. Magn., Vol. 43, No. 4, 1261-1264, Apr. 2007.

14. Ravaud, R. and G. Lemarquand, "Comparison of the Coulombian and Amperian current models for calculating the magnetic field produced by arc-shaped permanent magnets radially magnetized," Progress In Electromagnetics Research, Vol. 95, 309-327, 2009.

15. Ravaud, R., G. Lemarquand, V. Lemarquand, and C. Depollier, "Permanent magnet couplings: Field and torque three-dimensional expressions based on the Coulombian model," IEEE Trans. Magn., Vol. 45, No. 4, 1950-1958, Apr. 2009.

16. Ravaud, R., V. Lemarquand, and G. Lemarquand, "Analytical design of permanent magnet radial couplings," IEEE Trans. Magn., Vol. 46, No. 11, 3860-3865, Nov. 2010.

17. Smeets, J. P. C., T. T. Overboom, J. W. Jansen, and E. A. Lomonova, "Three-dimensional magnetic field modeling for coupling calculation between air-cored rectangular coils," IEEE Trans. Magn., Vol. 47, No. 10, 2935-2938, Oct. 2011.

18. Lubin, T., S. Mezani, and A. Rezzoug, "Exact analytical method for magnetic field computation in the air-gap of cylindrical electrical machines considering slotting effects," IEEE Trans. Magn., Vol. 46, No. 4, 1092-1099, Apr. 2010.

19. Lubin, T., S. Mezani, and A. Rezzoug, "Simple analytical expressions for the force and torque of axial magnetic couplings," IEEE Trans. Energy Convers., Vol 27, No. 2, 536-546, Jun. 2012.

20. Hornreich, R. M. and S. Shtrikman, "Optimal design of synchronous torque couplers," IEEE Trans. Magn., Vol. 14, No. 5, 800-802, Sep. 1978.

21. Azzouzi, J., G. Barakat, and B. Dakyo, "Quasi-3-D analytical modeling of the magnetic field of an axial flux permanent-magnet synchronous machine," IEEE Trans. Energy Convers., Vol. 20, No. 4, 746-752, Dec. 2005.

22. Tiegna, H., A. Bellara, Y. Amara, and G. Barakat, "Analytical modeling of the open-circuit magnetic field in axial flux permanent-magnet machines with semi-closed slots," IEEE Trans. Magn., Vol. 48, No. 3, 1212-1226, Mar. 2012.

23. De la Barrière, O., S. Hlioui, H. Ben Ahmed, M. Gabsi, and M. LoBue, "Three-dimensional analytical modeling of a permanent-magnet linear actuator with circular magnets," IEEE Trans. Magn., Vol. 45, No. 9, 3608-3616, Sep. 2010.

24. De la Barrière, O., S. Hlioui, H. Ben Ahmed, M. Gabsi, and M. LoBue, "3-D formal resolution of Maxwell equations for the computation of the no-load flux in an axial flux permanent-magnet synchronous machine," IEEE Trans. Magn., Vol. 48, No. 1, 128-136, Jan. 2012. 